\title{
Microwave processing: A potential technique for preparing NiO-YSZ composite and Ni-YSZ cermet
}

\author{
KANCHAN LATA SINGH, AJAY KUMAR, ANIRUDH P SINGH* and S S SEKHON ${ }^{\dagger}$ \\ Department of Applied Sciences and Humanities, Shaheed Bhagat Singh College of Engineering and Technology, \\ Ferozepur 152 004, India \\ ${ }^{\dagger}$ Department of Applied Physics, Guru Nanak Dev University, Amritsar 143 005, India
}

MS received 25 September 2007; revised 3 May 2008

\begin{abstract}
In the present study, microwave energy $(2.45 \mathrm{GHz})$ has been used to prepare nickel oxide-yttria stabilized zirconia (NiO-YSZ) composites of composition, $m \mathrm{NiO}-(1-m) \mathrm{Zr}_{0.9} \mathrm{Y}_{0.1} \mathrm{O}_{1.95}(m=0.2,0 \cdot 3,0 \cdot 4,0 \cdot 5$ and 0.6), from a precursor obtained by mixing $\mathrm{NiO}, \mathrm{Y}_{2} \mathrm{O}_{3}$ and monoclinic $\mathrm{ZrO}_{2}$ in their stoichiometric ratio. The composites have been prepared by conventional processing also to compare the products with those of microwave processed products. During comparison, it was observed that NiO-YSZ composites of each composition obtained by microwave processing had cubic phase of YSZ while in the conventionally prepared composites of compositions, $m=0 \cdot 2$ and $0 \cdot 3$, monoclinic, tetragonal and cubic phases of zirconia existed instead of its pure cubic phase. The composites were reduced to yield Ni-YSZ.
\end{abstract}

Keywords. Microwave processing; NiO-YSZ composites; cermet; XRD; SEM.

\section{Introduction}

An electrical composite is defined as a material comprising of two or more phases of electrical conductors. These conductors may be electronic, inert/insulating or ionic depending upon their charge carrier type. Some unusual electrical properties of composites formed by the mixture of two phases with different charge carrier species have been reported. The properties of a composite may be the average properties of its two constituents or those not seen for any of the constituent phases (Newnham 1986). The possibility of tailoring the properties of composites, particularly electrical properties, by controlling the relative volume fraction of phases has made them of great interest for technological applications (Wu and Liu 1997; Park and Choi 1999; Knauth and Tuller 2002; Kondo et al 2003). Nickel oxide yttria-stabilized zirconia (NiO-YSZ) composite is important due to its various technological applications, e.g. it is used as the starting material for the fabrication of Ni-YSZ anodes in solid oxide fuel cells (Minh 1993), in YSZ coatings (Khor and Guy 2000) or bonding to metals and in Ni-zirconia catalyst (Khor and Guy 2000; Qin and Derby 1992). It has been reported that the interactions of $\mathrm{NiO}$ and $\mathrm{YSZ}$ can occur during preparation of powders, sintering and even during operation (Chen and Shen 1989; Kuzjukevics et al 1996).

NiO-YSZ composite, a precursor of anode material, i.e. Ni-YSZ cermet, is usually prepared by mixed oxide

*Author for correspondence (anips123@rediffmail.com) method i.e. by mechanical mixing of commercial $\mathrm{NiO}$ and cubic YSZ powders. It is simple, but apt to give rise to a non-uniform distribution of the Ni-phase in the cermets causing poor performance. In order to have uniform distribution of $\mathrm{Ni}$ phase in the cermet, various chemical processes have been reported such as sol-gel (Marinsek et al 2000; Esposito et al 2003), complex formation with chelating agents (Duran et al 2003; Shao et al 2003), precipitation with buffer-solution of $\mathrm{NH}_{4} \mathrm{OH}$ and $\mathrm{NH}_{4} \mathrm{HCO}_{3}(\mathrm{Li}$ et al 2001), coat-mix (Simwonis et al 1999), liquid condensation process with thermoset polymer (Lee et al 2003), combustion synthesis (Aruna et al 1998; Marinsek et al 2002; Ringuede et al 2002), spray pyrolysis of slurry of YSZ in nickel acetate solution (Fukui et al 1998) and mechanofusion process (Jiang and Chan 2004). But due to lower processing cost, the mixed oxide method for the preparation of precursor is preferred to other methods.

In the recent past, it has been found that various chemical reactions are accelerated by microwave irradiation of reactants (Meek et al 1987; Sutton 1989; Mathis et al 1995; Cheng et al 1997; Vaidhyanathan et al 2001; Thakur et al 2002). Excellent reviews have been written to overview the developments in this rapidly growing field of microwave processing (Clark et al 1997; Roy et al 1997; Agrawal 1998). The major advantages of microwave processing are lower reaction temperatures and shorter processing time as compared to the conventional synthetic procedures. Generally, the majority of the reactions reported using microwave are in solution phases of the reactants. High dielectric loss tangents of the polar solvents are responsible 
for their effective coupling with the microwave field. Relatively, a few reports are available on the solid state synthesis of complex oxides using microwave. In the synthesis of $\mathrm{BaTiO}_{3}$ (Agrawal et al 1998), it has been observed that non-stoichiometry of $\mathrm{TiO}_{2}$ is responsible for the enhanced coupling of microwave. Also, in the synthesis of PZT, it has been reported that the use of stabilized zirconia and reduced $\mathrm{TiO}_{2}$ not only enhances the kinetics of formation of PZT, but changes the mechanism also (Vaidhyanathan et al 2001). Further, during the formation of fully cubic calcium stabilized zirconia, the higher diffusion of participating cations has been reported (Singh et al 2007). The reduction in the processing time and temperature is believed to be due to the higher diffusion rates induced by microwave field.

In most of the studies for the preparation of NiO-YSZ composites, the fully cubic stabilized YSZ has been used as the starting material and is mixed with $\mathrm{NiO}$, thereafter the mixture is calcined and sintered. In the present investigation, the microwave energy has been used for the first time to prepare NiO-YSZ composites of composition, $m \mathrm{NiO}-(1-m) \mathrm{Y}_{0.1} \mathrm{Zr}_{0.9} \mathrm{O}_{1.95}(m=0 \cdot 2,0 \cdot 3,0 \cdot 4,0.5$ and 0.6$)$, from the mixture of $\mathrm{NiO}, \mathrm{Y}_{2} \mathrm{O}_{3}$ and monoclinic $\mathrm{ZrO}_{2}$. The stoichiometry of $\mathrm{ZrO}_{2}$ and $\mathrm{Y}_{2} \mathrm{O}_{3}$ is maintained such that it results in YSZ phase of composition, $\mathrm{Y}_{0.1} \mathrm{Zr}_{0.9} \mathrm{O}_{1.95}$, in each of the composites mentioned above. The composites of the same compositions as mentioned above have been prepared by conventional heating also. The composites, $m \mathrm{NiO}-(1-m) \mathrm{Y}_{0.1} \mathrm{Zr}_{0.9} \mathrm{O}_{1.95}$, obtained by the microwave as well as the conventional heating processes have been reduced in the hydrogen atmosphere to convert them into $\mathrm{Ni}-$ YSZ cermets of respective compositions. The characteristics of microwave processed products have been compared with those of the conventionally processed products in order to investigate the potentiality of microwave energy in the fabrication of NiO-YSZ composites and $\mathrm{Ni}-\mathrm{YSZ}$ cermets.

\section{Experimental}

$90 \mathrm{Mol} \%$ of monoclinic $\mathrm{ZrO}_{2}$ and $10 \mathrm{~mol} \%$ of $\mathrm{YO}_{3 / 2}$ were taken and mixed for $6 \mathrm{~h}$ by ball milling using zirconia ball and acetone as the grinding medium resulting in a powder of composition, $\mathrm{Zr}_{0.9} \mathrm{Y}_{0.1} \mathrm{O}_{1.95}$, now hereafter termed as YSZ. Precursors of five compositions for $\mathrm{NiO}$ YSZ composites i.e. $m \mathrm{NiO}-(1-m) \mathrm{Y}_{0.1} \mathrm{Zr}_{0.9} \mathrm{O}_{1.95}(m=0.2$, $0.3,0.4,0.5$ and 0.6 ) were prepared by mixing $\mathrm{NiO}$ with the already prepared YSZ. The stoichiometry of $\mathrm{NiO}$ and YSZ mixture were taken for the composition of $m \mathrm{NiO}$ $(1-m) \mathrm{Y}_{0.1} \mathrm{Zr}_{0.9} \mathrm{O}_{1.95}(m=0.2,0.3,0.4,0.5$ and 0.6$)$ and again ball milled for $6 \mathrm{~h}$ using zirconia ball and acetone as the grinding medium. After drying, the powders were mixed with $4 \%$ poly vinyl alcohol (PVA) solution and were consolidated in the cylindrical green pellets at $200 \mathrm{MPa}$ by uniaxial pressing. The PVA from the green pellets was removed by heating them at $500^{\circ} \mathrm{C}$ for $6 \mathrm{~h}$ before sintering. The green pellets, five pellets of each composition, were taken in alumina crucible and were covered with $8 \%$ PVA solution. The PVA solution acts as a susceptor (Singh et al 2007) to preheat the samples so that they could absorb microwave energy. They were fired at $1400^{\circ} \mathrm{C}$ for 15 min with microwave energy of $2.45 \mathrm{GHz}$. In this study, platinum shielded $S$-type $\mathrm{Pt}-10 \% \mathrm{Rh} / \mathrm{Pt}$ thermocouple was used to measure temperature. The thermocouple was properly shielded and grounded to avoid the microwave interference with the thermocouple and to get reliable temperature readings. The thermocouple was fitted in the microwave so that the tip of the thermocouple was $1 \mathrm{~mm}$ away from the work piece in the sintering packet. A voltage system consisting of two variacs was added to the power supply of the magnetron to control the heating rate and to achieve the required temperature for desired exposure time. The temperature of the sample was measured with an accuracy of $\pm 1{ }^{\circ} \mathrm{C}$ during processing.

Another set of green pellets, five pellets of each composition, were fired at $1400^{\circ} \mathrm{C}$ for $4 \mathrm{~h}$ by the conventional heating also for comparison purpose. The fired products obtained after microwave processing and conventional processing were reduced in the presence of mixture of $5 \%$ $\mathrm{H}_{2}$ and $95 \%$ Ar at $800^{\circ} \mathrm{C}$ for $4 \mathrm{~h}$ to convert $\mathrm{NiO}-\mathrm{YSZ}$ composites to Ni-YSZ cermets. Thus, four types of samples, each having five compositions corresponding to $m=0.2,0 \cdot 3,0 \cdot 4,0.5$ and 0.6 , were prepared in all. These types of samples were designated as $m \mathrm{NiO}-\mathrm{YSZ} \mathrm{MW}$ for composites obtained from microwave processed $m \mathrm{NiO}$ $(1-m) \mathrm{Y}_{0.1} \mathrm{Zr}_{0.9} \mathrm{O}_{1.95}$ precursors, $m \mathrm{NiO}-\mathrm{YSZ} \mathrm{CON}$ for composites obtained from conventionally processed $m \mathrm{NiO}-$ $(1-m) \mathrm{Y}_{0.1} \mathrm{Zr}_{0.9} \mathrm{O}_{1.95}$ precursors, $m \mathrm{Ni}-\mathrm{YSZ} \mathrm{MW}$ for reduced $m \mathrm{NiO}-\mathrm{YSZ} \mathrm{MW}$ and $m \mathrm{Ni}-\mathrm{YSZ} \mathrm{CON}$ for reduced $m \mathrm{NiO}-\mathrm{YSZ} \mathrm{CON}$. The phase changes in the samples obtained after microwave processing and conventional processing, and their reduced products were investigated by X-ray diffraction technique (X-ray Diffractometer, Model: Bruker AXS, D-8 Advance, Switzerland). The pellets were polished with diamond paste and their microstructures were studied by SEM (Scanning Electron Microscope, Model: LEO 435 VP, Cambridge, UK). The energy dispersive X-ray (EDAX) analysis was done by taking FESEM (FEI, Model Quanta 200F, The Netherlands) which was used to study distribution of alloying elements in $\mathrm{NiO}-\mathrm{YSZ}$ composites.

\section{Results and discussion}

The precursors of $m \mathrm{NiO}-(1-m) \mathrm{Y}_{0.1} \mathrm{Zr}_{0.9} \mathrm{O}_{1.95}(m=0 \cdot 2,0 \cdot 3$, $0.4,0.5$ and 0.6 ) composites prepared by ball milling were black in colour. The sintered pellets of each composition obtained after microwave firing at $1400^{\circ} \mathrm{C}$ for $15 \mathrm{~min}$ as well as conventional firing at $1400^{\circ} \mathrm{C}$ for $4 \mathrm{~h}$ were found 
to be green in colour. The Ni-YSZ cermets obtained after reduction of microwave and conventionally processed $\mathrm{NiO}-\mathrm{YSZ}$ composites were black in colour.

Figure 1 shows XRD patterns of microwave processed $\mathrm{Y}_{0.1} \mathrm{Zr}_{0.9} \mathrm{O}_{1.95}$ along with the microwave processed composites ( $m$ NiO-YSZ MW). Figure 2 shows XRD patterns of conventionally processed $\mathrm{Y}_{0.1} \mathrm{Zr}_{0.9} \mathrm{O}_{1.95}$ along with conventionally processed composites ( $m \mathrm{NiO}-\mathrm{YSZ} \mathrm{CON})$. The XRD patterns of cermet $m \mathrm{Ni}-\mathrm{YSZ} \mathrm{MW}$ and cermet $m \mathrm{Ni}-\mathrm{YSZ} \mathrm{CON}$ are shown in figures 3 and 4 , respectively. Different phases of zirconia (monoclinic, tetragonal and cubic) and phases of $\mathrm{NiO}$ and $\mathrm{Ni}$ have been identified in the XRD patterns.

In figures 1 and 2, the presence of cubic phase of zirconia and $\mathrm{NiO}$ cubic phase have been identified from the (111) peak and (200) peak, respectively whereas the presence of monoclinic phase of zirconia has been identified by $(11 \overline{1})$ peak. Since the $2 \theta$ for (111) peak of tetragonal

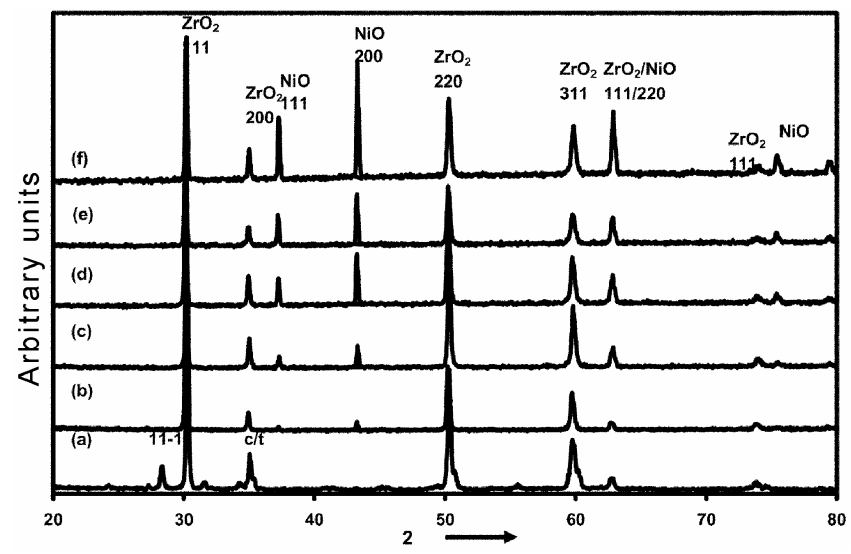

Figure 1. XRD patterns of microwave processed (a) $\mathrm{Zr}_{0.9} \mathrm{Y}_{0.1} \mathrm{O}_{1.95}$, (b) 0.2NiO-YSZ MW, (c) 0.3NiO-YSZ MW, (d) $0.4 \mathrm{NiO}-\mathrm{YSZ} \mathrm{MW}$, (e) $0.5 \mathrm{NiO}-\mathrm{YSZ} \mathrm{MW}$ and (f) $0.6 \mathrm{NiO}-\mathrm{YSZ}$ MW

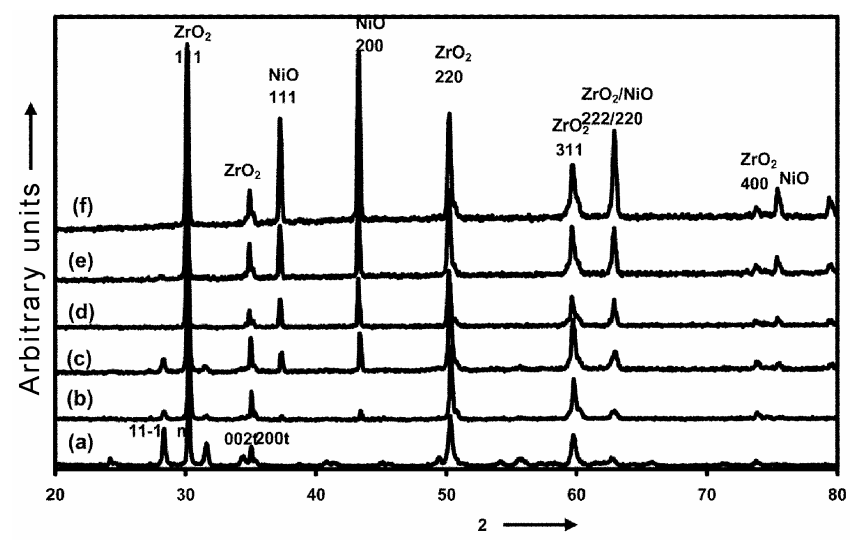

Figure 2. $\mathrm{XRD}$ patterns of conventionally processed (a) $\mathrm{Zr}_{0.9} \mathrm{Y}_{0.1} \mathrm{O}_{1.95}$, (b) $0 \cdot 2 \mathrm{NiO}-\mathrm{YSZ} \mathrm{CON}$, (c) $0 \cdot 3 \mathrm{NiO}-\mathrm{YSZ} \mathrm{CON}$, (d) $0.4 \mathrm{NiO}-\mathrm{YSZ} \mathrm{CON}$, (e) $0.5 \mathrm{NiO}-\mathrm{YSZ} \mathrm{CON}$ and (f) $0.6 \mathrm{NiO}-$ YSZ CON. and cubic phase is almost same, therefore, the tetragonal phase has been distinguished from cubic phase by separation of (002) and (200) peaks of the tetragonal structure. In the $\mathrm{Ni}-\mathrm{YSZ}$ cermets, the presence of $\mathrm{Ni}$ phase has been identified from (200) peak in figures 3 and 4 while cubic and monoclinic phases of zirconia were identified by (111)

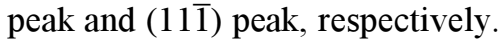

The XRD pattern of microwave processed $\mathrm{Zr}_{0.9} \mathrm{Y}_{0.1} \mathrm{O}_{1.95}$

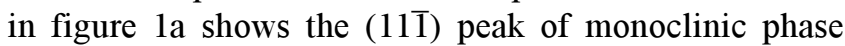
and (111) peak of tetragonal and cubic phases of zirconia. The existence of tetragonal phase could be distinguished from cubic phase by the presence of (002) and (200) peaks of the tetragonal structure. The XRD patterns of composites, $m \mathrm{NiO}-\mathrm{YSZ} \mathrm{MW}(m=0.2,0 \cdot 3,0 \cdot 4,0.5$ and $0 \cdot 6)$, in figure $1(b-f)$ show the peaks due to the presence of cubic zirconia and $\mathrm{NiO}$ only. The presence of tetragonal zirconia in composites of all compositions is ruled out as no corresponding peaks appear in the XRD patterns. It shows that the zirconia component is fully cubic in $m \mathrm{NiO}$

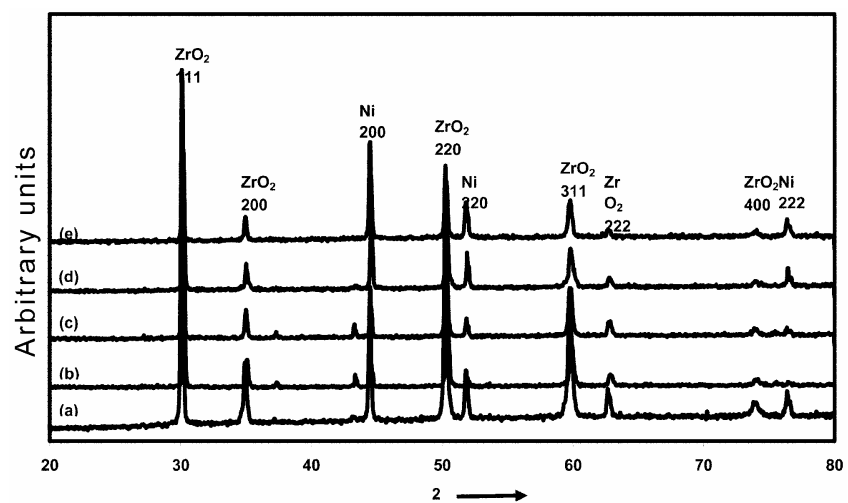

Figure 3. XRD patterns of cermets obtained from microwave processed composites, $m \mathrm{NiO}-(1-m) \mathrm{YSZ}$ : (a) $0 \cdot 2 \mathrm{Ni}-\mathrm{YSZ} \mathrm{MW}$, (b) $0.3 \mathrm{Ni}-Y S Z \mathrm{MW}$, (c) $0.4 \mathrm{Ni}-\mathrm{YSZ} \mathrm{MW}$, (d) $0.5 \mathrm{Ni}-\mathrm{YSZ} \mathrm{MW}$ and (e) $0 \cdot 6 \mathrm{Ni}-\mathrm{YSZ} \mathrm{MW}$.

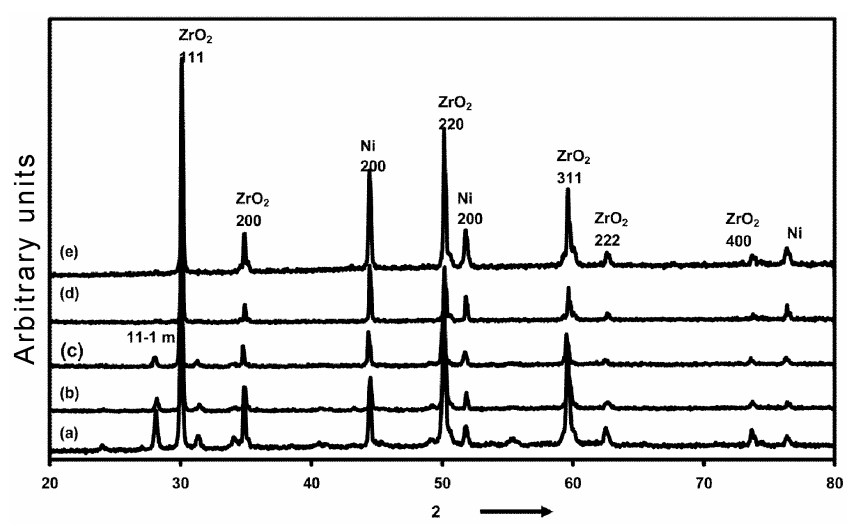

Figure 4. XRD patterns of cermets obtained from conventionally processed composites, $m \mathrm{NiO}-(1-m) \mathrm{YSZ}$ : (a) $0 \cdot 2 \mathrm{Ni}-$ YSZ CON, (b) $0.3 \mathrm{Ni}-\mathrm{YSZ} \mathrm{CON}$, (c) $0.4 \mathrm{Ni}-\mathrm{YSZ} \mathrm{CON}$, (d) $0 \cdot 5 \mathrm{Ni}-\mathrm{YSZ} \mathrm{CON}$ and (e) $0.6 \mathrm{Ni}-\mathrm{YSZ} \mathrm{CON}$. 
Table 1. Lattice parameters of $m \mathrm{NiO}-\mathrm{YSZ} \mathrm{MW}$ and $m \mathrm{NiO}-\mathrm{YSZ} \mathrm{CON}$.

\begin{tabular}{|c|c|c|c|}
\hline \multicolumn{2}{|c|}{ Microwave processed } & \multicolumn{2}{|c|}{ Conventionally processed } \\
\hline Sample & Lattice parameter $(\mathrm{nm})$ & Sample & Lattice parameter $(\mathrm{nm})$ \\
\hline 20NiO-YSZ MW & $0 \cdot 5132$ & $20 \mathrm{NiO}-\mathrm{YSZ} \mathrm{CON}$ & $0 \cdot 5132$ \\
\hline 30NiO-YSZ MW & 0.5133 & $30 \mathrm{NiO}-\mathrm{YSZ} \mathrm{CON}$ & 0.5133 \\
\hline 40NiO-YSZ MW & 0.5133 & 40NiO-YSZ CON & 0.5132 \\
\hline 50NiO-YSZ MW & 0.5133 & $50 \mathrm{NiO}-\mathrm{YSZ} \mathrm{CON}$ & 0.5134 \\
\hline 60NiO-YSZ MW & 0.5132 & 60NiO-YSZ MW & $0 \cdot 5132$ \\
\hline
\end{tabular}
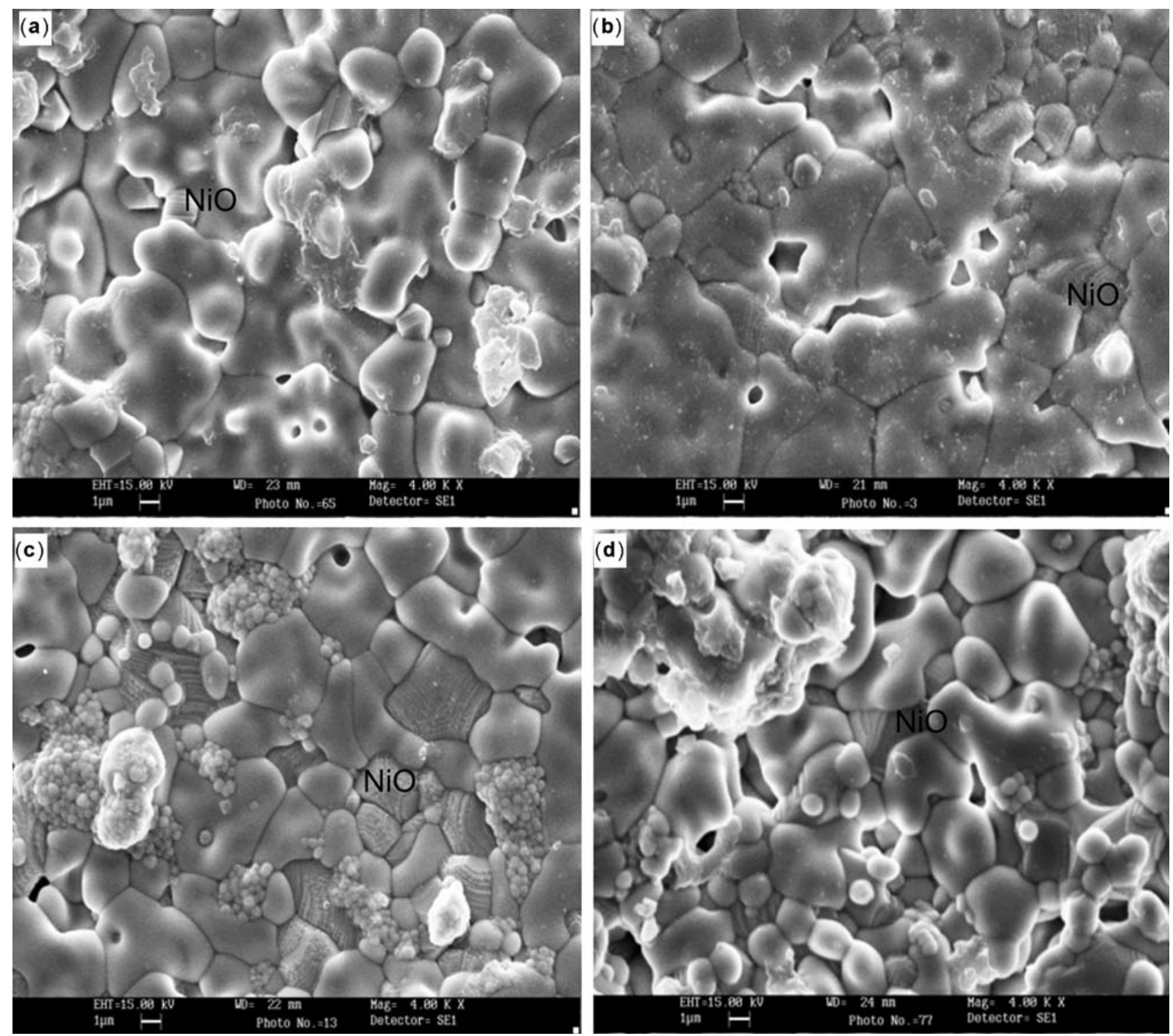

Figure 5. Scanning electron micrographs of microwave processed composites, $m \mathrm{NiO}-(1-m) \mathrm{YSZ}$ : (a) $0 \cdot 2 \mathrm{NiO}-\mathrm{YSZ}$ MW, (b) $0.3 \mathrm{NiO}-\mathrm{YSZ} \mathrm{MW}$, (c) $0.4 \mathrm{NiO}-\mathrm{YSZ} \mathrm{MW}$ and (d) $0.5 \mathrm{NiO}-\mathrm{YSZ} \mathrm{MW}$.

$(1-m)$ YSZ MW composites of all compositions prepared by microwave processing.

The XRD patterns of conventionally processed $\mathrm{Zr}_{0.90}$ $\mathrm{Y}_{0.10} \mathrm{O}_{1 \cdot 94}, 0 \cdot 2 \mathrm{NiO}-\mathrm{YSZ} \mathrm{CON}$ and $0 \cdot 3 \mathrm{NiO}-\mathrm{YSZ} \mathrm{CON}$ in figures $2 \mathrm{a}, \mathrm{b}$ and $\mathrm{c}$, respectively show presence of monoclinic phase, tetragonal phase and cubic phase of zirconia. The cubic and tetragonal phases of zirconia cannot be distinguished by their (111) peak. However, 002 and 200 peaks of tetragonal phases are visible in figures $2 a, b$ and $c$. The amount of monoclinic phase decreases as the concentration of $\mathrm{NiO}$ increases and disappears in the composition of $0.4 \mathrm{NiO}-\mathrm{YSZ} \mathrm{CON}$ and other composition of higher $\mathrm{NiO}$ content. The coexistence of tetragonal and cubic phases cannot be ruled out in $0 \cdot 4 \mathrm{NiO}-\mathrm{YSZ} \mathrm{CON}, 0 \cdot 5 \mathrm{NiO}-$ 

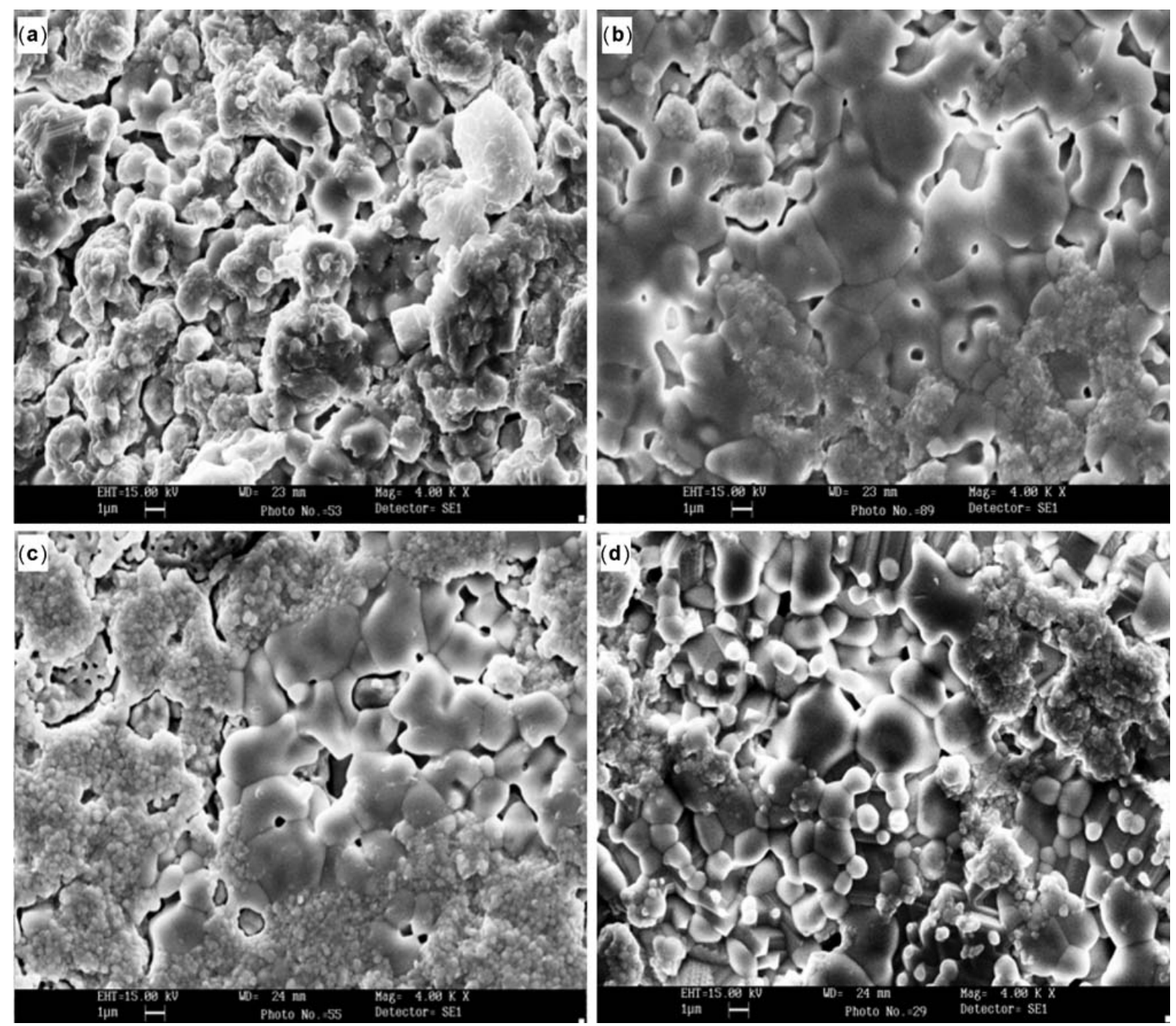

Figure 6. Scanning electron micrographs of conventionally processed composites, $m \mathrm{NiO}-(1-m) \mathrm{YSZ}$ : (a) $20 \mathrm{NiO}-\mathrm{YSZ}$ CON, (b) $30 \mathrm{NiO}-Y S Z \mathrm{CON}$, (c) $40 \mathrm{NiO}-\mathrm{YSZ} \mathrm{CON}$ and (d) $50 \mathrm{NiO}-\mathrm{YSZ} \mathrm{CON}$.

YSZ CON and $0 \cdot 6 \mathrm{NiO}-\mathrm{YSZ} \mathrm{CON}$ as the peak between $2 \theta=34$ and 36 is broad which may be due to the presence of the tetragonal phase.

Table 1 shows the lattice parameter of $m \mathrm{NiO}-(1-m)$ YSZMW and $m \mathrm{NiO}-(1-m)$ YSZ CON calculated from (111) peak of each sample.

The XRD patterns of cermet $m \mathrm{Ni}-\mathrm{YSZ} \mathrm{MW}$ in figure $3(\mathrm{a}-\mathrm{e})$ shows that all the peaks due to $\mathrm{NiO}$ have disappeared after the reduction and only the peaks corresponding to Ni and cubic YSZ are present. This means that all the $m \mathrm{NiO}-\mathrm{YSZ} \mathrm{MW}$ composite particles were transformed successfully to $m \mathrm{Ni}-\mathrm{YSZ}$ MW cermet under reducing condition. The crystal structure of zirconia remains to be cubic in cermet $m \mathrm{Ni}-\mathrm{YSZ} \mathrm{MW}$ for all compositions. The XRD patterns of $m \mathrm{Ni}-\mathrm{YSZ} \mathrm{CON}$ in figure 4 (a-e) shows that $\mathrm{NiO}$ of $m \mathrm{NiO}-\mathrm{YSZ} \mathrm{CON}$ composites has reduced to $\mathrm{Ni}$ in all compositions of cermet $m \mathrm{Ni}-\mathrm{YSZ} \mathrm{CON}$. The monoclinic phase of zirconia persists in $0 \cdot 2 \mathrm{Ni}-\mathrm{YSZ} \mathrm{CON}$ and $0 \cdot 3 \mathrm{Ni}-\mathrm{YSZ} \mathrm{CON}$ which is present in their respective composites also. The monoclinic phase of zirconia also precipitates in cermet $0.4 \mathrm{Ni}-\mathrm{YSZ} \mathrm{CON}$ unlike in its corresponding composite, $0 \cdot 4 \mathrm{NiO}-\mathrm{YSZ} \mathrm{CON}$. In the $m \mathrm{Ni}-$ YSZ for $m=0.5$ and $0 \cdot 6$, the crystal structure of zirconia remains to be cubic.

The scanning electron micrographs of microwave processed composites, $m \mathrm{NiO}-\mathrm{YSZ} \mathrm{MW}$ for $m=0 \cdot 2,0 \cdot 3,0 \cdot 4$ and $0 \cdot 5$, are shown in figure $5(\mathrm{a}-\mathrm{d})$. In the SEM of figure $5(\mathrm{a}-\mathrm{d})$, the NiO phase is identified by its stripped surface (Parks and Choi 1999). Figure 5a shows the uniform distribution of YSZ and particles of $\mathrm{NiO}$ are also seen. It appears from the SEM (figure $5 \mathrm{~b}$ ) of $0.3 \mathrm{NiO}-\mathrm{YSZ} \mathrm{MW}$ that the grain growth of YSZ has increased and at the same time agglomeration of $\mathrm{NiO}$ particles is also seen. The grains of YSZ and $\mathrm{NiO}$ are of nearly same size at $40 \mathrm{~mol} \%$ $(m=0.4)$ of $\mathrm{NiO}$ in YSZ. Further, in this sample the stripped surface of $\mathrm{NiO}$ is quite distinct and particles of 

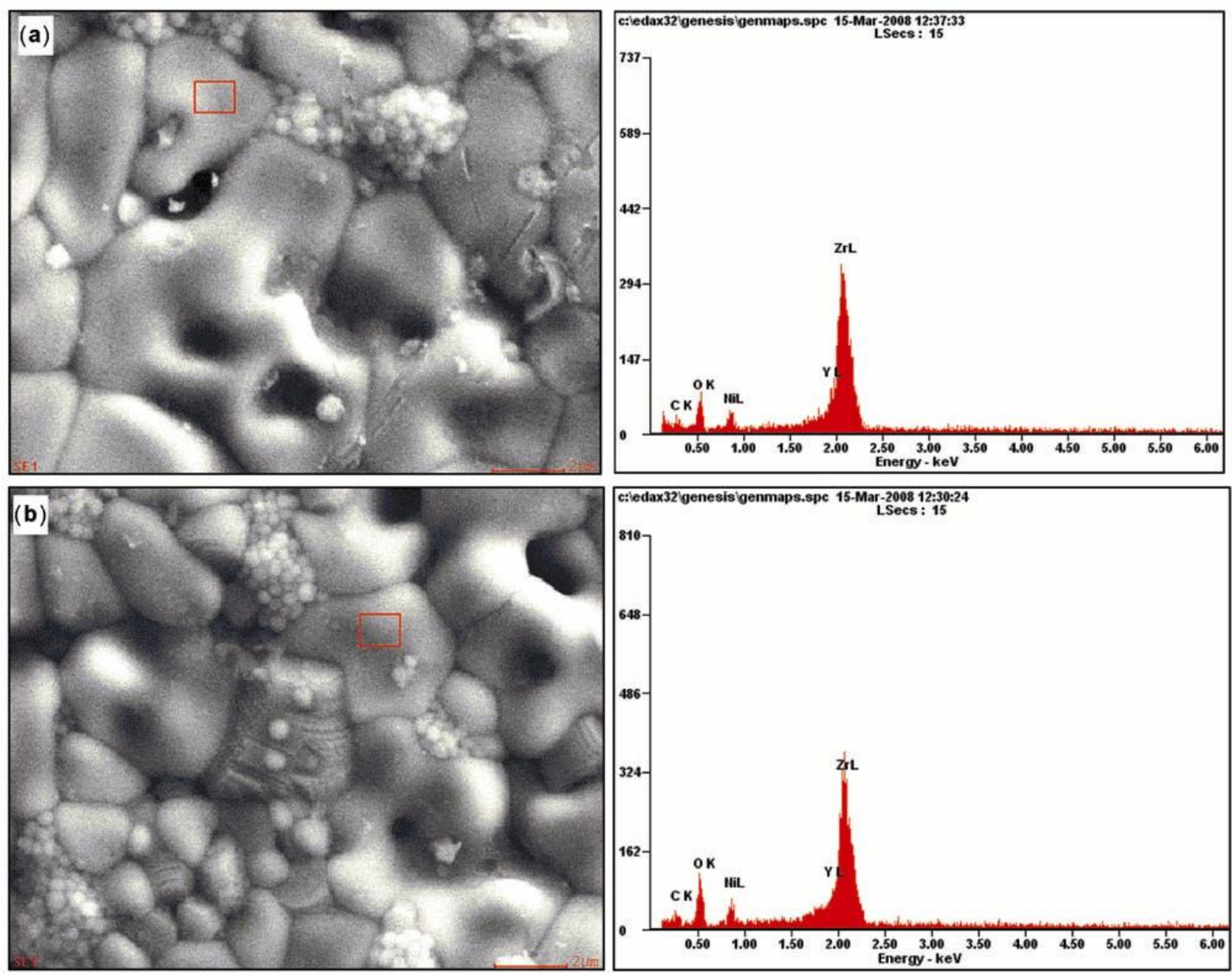

Figure 7. FESEM and EDAX of (a) $0 \cdot 2 \mathrm{NiO}-\mathrm{YSZ}$ MW and (b) 0.3NiO-YSZ MW.

YSZ and $\mathrm{NiO}$ are uniformly distributed similar to the result reported by Park and Choi (1999). However, the agglomeration of $\mathrm{NiO}$ has also increased as the content of $\mathrm{NiO}$ is increased in YSZ.

The scanning electron micrographs of conventionally sintered composites, $m \mathrm{NiO}-\mathrm{YSZ} \mathrm{CON}$ for $m=0 \cdot 2,0 \cdot 3$, 0.4 and 0.5 , are shown in figure $6(\mathrm{a}-\mathrm{d})$. The SEM of conventionally sintered composites, $m \mathrm{NiO}-\mathrm{YSZ} \mathrm{CON}$, as shown in figure 6 reveals that the agglomeration of $\mathrm{NiO}$ is more even in the $0 \cdot 2 \mathrm{NiO}-\mathrm{YSZ} \mathrm{CON}$ composite unlike in microwave sintered $0 \cdot 2 \mathrm{NiO}-\mathrm{YSZ} \mathrm{MW}$ composite in which the distribution of $\mathrm{NiO}$ and $\mathrm{YSZ}$ is uniform. Also, the grain growth of YSZ in this conventionally sintered composite is low as compared to that of $0 \cdot 2 \mathrm{NiO}-\mathrm{YSZ} \mathrm{MW}$ microwave sintered composite. In the $0 \cdot 3 \mathrm{NiO}-\mathrm{YSZ} \mathrm{CON}$, the grain growth of YSZ has initiated and also the agglomeration of $\mathrm{NiO}$ can be seen there. The XRD patterns of $0.2 \mathrm{NiO}-\mathrm{YSZ} \mathrm{CON}$ and $0.3 \mathrm{NiO}-\mathrm{YSZ} \mathrm{CON}$ show the presence of monoclinic phase as shown in figures $2 \mathrm{a}$ and b. The presence of monoclinic phase, as observed in XRD pattern of these samples, causes poor densification of the samples, which is evident in the SEM of conventionally sintered composites of $0 \cdot 2 \mathrm{NiO}-\mathrm{YSZ} \mathrm{CON}$ and $0 \cdot 3 \mathrm{NiO}-$ YSZ CON shown in figures $6 a$ and $b$.

The dissolution of $\mathrm{NiO}$ and $\mathrm{Y}_{2} \mathrm{O}_{3}$ in zirconia in samples $0 \cdot 2 \mathrm{NiO}-\mathrm{YSZ} \mathrm{MW}, 0 \cdot 3 \mathrm{NiO}-\mathrm{YSZ} \mathrm{MW}, 0 \cdot 2 \mathrm{NiO}-\mathrm{YSZ} \mathrm{CON}$ and $0.3 \mathrm{NiO}-\mathrm{YSZ} \mathrm{CON}$ was estimated by EDAX and compared. The amount of $\mathrm{Y}_{2} \mathrm{O}_{3}$ dissolved in $\mathrm{ZrO}_{2}$ could not be ascertained in any of the above samples as the peaks of zirconium and yttrium overlap because their atomic numbers are close to each other. However, yttrium is present in grains of zirconium of each sample as shown in figures 7 and 8 . The dissolution of $\mathrm{NiO}$ in $0 \cdot 2 \mathrm{NiO}-\mathrm{YSZ} \mathrm{MW}$ and $0 \cdot 3 \mathrm{NiO}-\mathrm{YSZ} \mathrm{MW}$ is higher as compared to those of $0 \cdot 2 \mathrm{NiO}-\mathrm{YSZ} \mathrm{CON}$ and $0 \cdot 3 \mathrm{NiO}-\mathrm{YSZ} \mathrm{CON}$ as shown in figures $7(a, b)$ and $8(a, b)$.

Kuzjukevics and Linderoth (1997) prepared NiO-YSZ composites from oxides of $\mathrm{NiO}, \mathrm{Y}_{2} \mathrm{O}_{3}$ and $\mathrm{ZrO}_{2}$ by plasma synthesis. It has been inferred that $\mathrm{NiO}$ promotes the formation of cubic zirconia by dissolving $\mathrm{NiO}$ in $\mathrm{ZrO}_{2}$, as the dissolution of $\mathrm{NiO}$ in YSZ significantly decreases the lattice parameter of cubic zirconia due to smaller ionic radius of $\mathrm{Ni}^{2+}$ in comparison to both the $\mathrm{Zr}^{4+}$ and $\mathrm{Y}^{3+}$. Further, the decrease in the lattice parameter of 

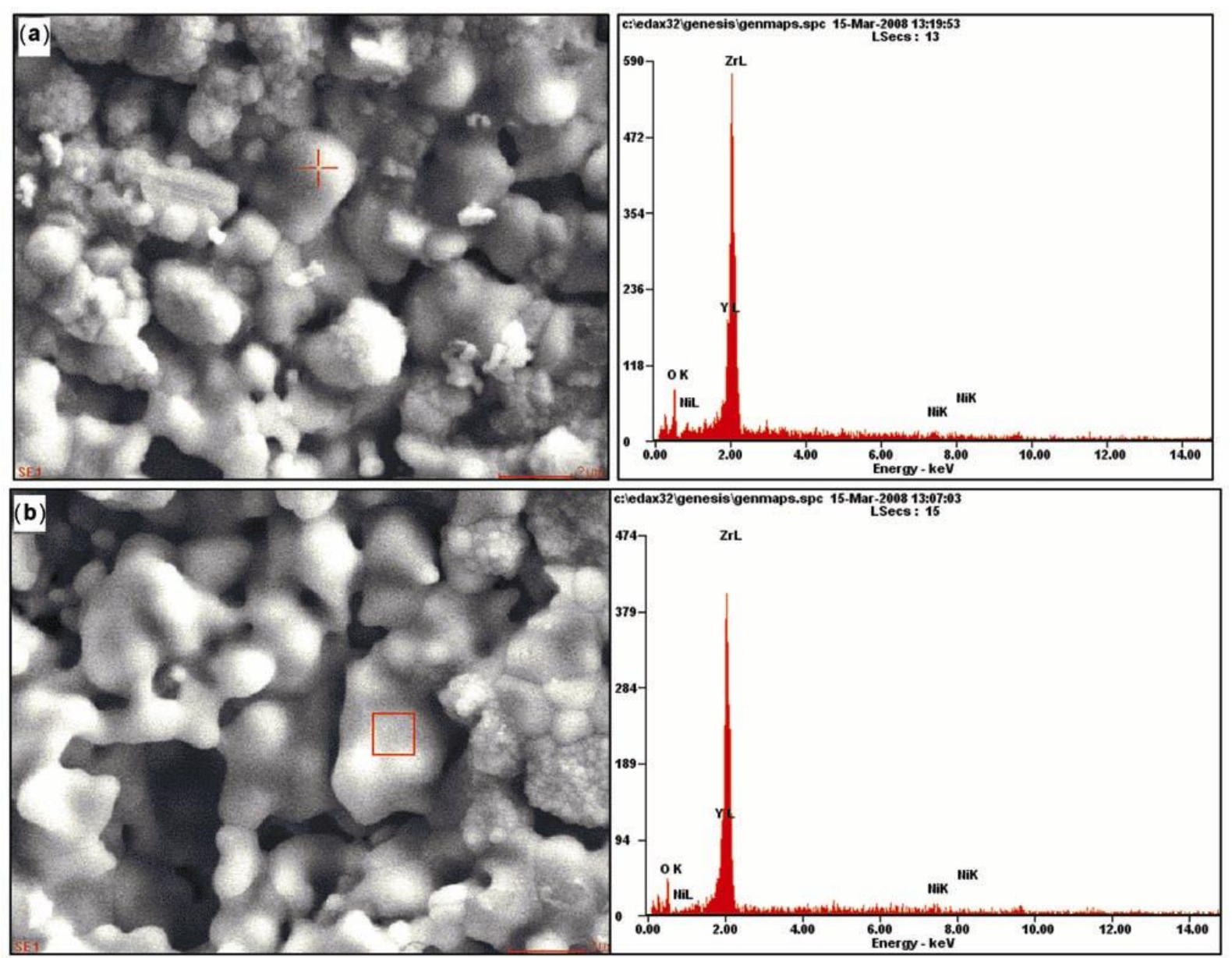

Figure 8. FESEM and EDAX of (a) $0 \cdot 2 \mathrm{NiO}-\mathrm{YSZ} \mathrm{CON}$ and (b) $0 \cdot 3 \mathrm{NiO}-\mathrm{YSZ} \mathrm{CON}$.

YSZ is a function of $\mathrm{NiO}$ concentration and the maximum limit of dissolution of $\mathrm{NiO}$ in $\mathrm{YSZ}$ is $\leq 5 \mathrm{~mol} \%$ (Chen et al 1992). In the present work, the lattice parameter value of composites were found to be lower than the previously reported data of fully cubic YSZ of composition, $\mathrm{Zr}_{0.9} \mathrm{Y}_{0.1} \mathrm{O}_{1.95}$ (Ingel and Lewis 1986), however, the value of lattice parameter remained almost constant with the increase in $\mathrm{NiO}$ content (table 1) for microwave processed composites. Since zirconia is a mixture of its tetragonal, cubic and monoclinic phases in the samples, $0 \cdot 2 \mathrm{NiO}-\mathrm{YSZ} \mathrm{CON}$ and $0 \cdot 3 \mathrm{NiO}-\mathrm{YSZ} \mathrm{CON}$, whereas in the tetragonal and cubic phases in $0.4 \mathrm{NiO}-\mathrm{YSZ} \mathrm{CON}$, $0.5 \mathrm{NiO}-\mathrm{YSZ} \mathrm{CON}$ and $0.6 \mathrm{NiO}-\mathrm{YSZ} \mathrm{CON}$, the value of the lattice parameter observed could not be interpreted which may be due to the compositional fluctuations. These results suggest that the dissolution of $\mathrm{NiO}$ occurs during microwave processing, but the solubility of $\mathrm{NiO}$ does not increase with the increase in $\mathrm{NiO}$ concentration.

From figures $1 \mathrm{a}$ and $\mathrm{b}$, it is evident that the dissolution of $10 \mathrm{~mol} \%$ of $\mathrm{YO}_{1.5}$ is not sufficient to stabilize cubic phase of YSZ by microwave processing as well as conventional processing, but gives partially stabilized zirconia phase of YSZ (Y-PSZ). Also, the percentage of monoclinic phase in partially stabilized zirconia obtained by conventional processing is $47 \%$ while in that obtained by microwave processing is $17 \%$ (Singh et al 2008). This shows that the dissolution of $\mathrm{Y}_{2} \mathrm{O}_{3}$ in $\mathrm{ZrO}_{2}$ is less during conventional processing than that of microwave processing (Singh et al 2008).

In the present study of the conventional processing, the formation of almost cubic phase of YSZ was observed only in composites, $m \mathrm{NiO}-\mathrm{YSZ} \mathrm{CON}$ with $m>0 \cdot 3$. This suggests that the introduction of $\mathrm{NiO}$ in sufficient amount $(m>0.3)$ enhances the stabilization of zirconia in YSZ even at lower $\mathrm{Y}_{2} \mathrm{O}_{3}$ concentration by promoting $\mathrm{Y}_{2} \mathrm{O}_{3}$ diffusion along with $\mathrm{NiO}$ on lattice site of $\mathrm{ZrO}_{2}$. This observation has already been reported by Kuzjukevics and Linderoth (1997) and Chen et al (1994). However, $\mathrm{NiO}$ alone is not a stabilizer of cubic zirconia (Chen and Shen 1989). In case of the microwave processing, the cubic phase of YSZ formed even with $20 \mathrm{~mol} \%(m \geq 0 \cdot 2)$ of $\mathrm{NiO}$. It appears that the presence of microwave field increases the probability of diffusion of $\mathrm{Y}_{2} \mathrm{O}_{3}$ along with $\mathrm{NiO}$ on lattice site of $\mathrm{ZrO}_{2}$. It suggests that the diffusion of ions 
in the microwave processing is controlled by some additional factors also other than the thermal diffusion (Singh et al 2007).

In this work, the firing in either microwave processing or conventional processing involves solid state reaction between $\mathrm{NiO}, \mathrm{Y}_{2} \mathrm{O}_{3}$ and $\mathrm{ZrO}_{2}$ resulting in chemical homogenization accompanied by sintering. Chemical homogenization influences the microstructure of the product. It is evident from XRDs in figure 1 that microwave processing has led to the formation of two-phase composite that includes cubic YSZ and $\mathrm{NiO}$ i.e. $m \mathrm{NiO}-(1-m) \mathrm{YSZ} \mathrm{MW}$ composite $(m=0.2,0.3,0.4,0.5$ and 0.6$)$. Therefore, their SEM in figure $5(\mathrm{a}-\mathrm{d})$ shows very clear grain boundaries. In the composites, $m \mathrm{NiO}-(1-m) \mathrm{YSZ} \mathrm{CON}$, having compositions $m=0.2$ and $0 \cdot 3$, the solid solution forma- tion of YSZ is not complete. The compositional inhomogeneity is evident from their respective SEMs in figures 6a and $b$ due to presence of the monoclinic phase of zirconia which are only partially sintered with a loose particle cloud. It is evident from above discussion that $\mathrm{NiO}$ behaves in different ways during microwave processing, since the presence of microwave facilitates the formation of solid solution of $\mathrm{Y}_{2} \mathrm{O}_{3}$ and $\mathrm{ZrO}_{2}$ to have cubic YSZ. In the conventional processing, cubic YSZ does not form for $m=0.2$ and $0 \cdot 3$.

The solid state reactions in conventional furnaces generally take place under isothermal conditions where the transfer of heat occurs from the heating elements of the furnace to the sample. The individual phases in a multiphase sample is heated more or less to the same temperature
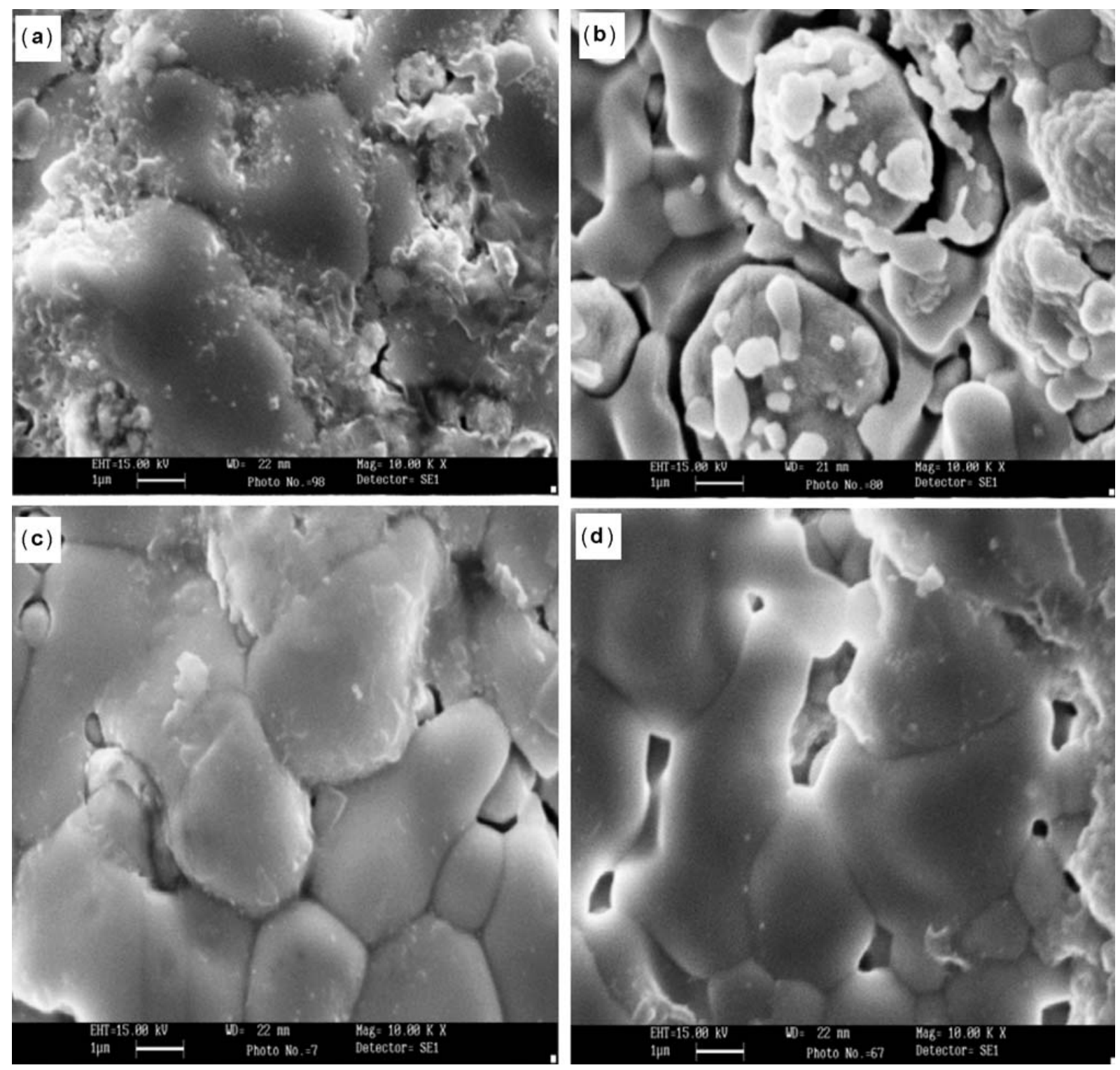

Figure 9. Scanning electron micrographs of cermets: (a) $0 \cdot 3 \mathrm{Ni}-\mathrm{YSZ} \mathrm{MW},(\mathbf{b}) 0 \cdot 3 \mathrm{Ni}-\mathrm{YSZ} \mathrm{CON},(\mathbf{c}) 0 \cdot 4 \mathrm{Ni}-\mathrm{YSZ} \mathrm{MW}$ and (d) $0.4 \mathrm{Ni}-\mathrm{YSZ} \mathrm{CON}$. 
as that of the furnace, a situation known as isothermal heating. However, in the case of microwave heating, due to differences in the microwave absorption, the individual phase is heated up to different temperatures at different rates creating a unique situation which is referred to as 'anisothermal heating' (Peelamedu et al 2003; Yadoji et al 2003). The species which achieves higher temperature works as micro heat sources and species having lower temperature works as micro heat sinks. A large temperature difference between the constituent phases leads to a reaction path and diffusion mechanisms different from those of conventional isothermal heating. The model experiment of Roy and co-workers (Peelamedu et al 2001) has established that the anisothermal reactions in the $\mathrm{Y}_{2} \mathrm{O}_{3}-\mathrm{Fe}_{3} \mathrm{O}_{4}$ system involve a predominant one-directional diffusion of $\mathrm{Fe}_{3} \mathrm{O}_{4}\left(\mathrm{Fe}_{3} \mathrm{O}_{4}\right.$ is a microwave susceptor) towards $\mathrm{Y}_{2} \mathrm{O}_{3}$ as compared to a mutual diffusion that generally takes place in the conventional, isothermal reactions. Given the fact that the $\mathrm{NiO}$ being a magnetic material, is a microwave susceptor (Meek et al 1987) and works as heat source and other constituent as heat sink. This will lead to anisothermal behaviour of $\mathrm{NiO}$ in $\mathrm{NiO}-\mathrm{Y}_{2} \mathrm{O}_{3}-$ $\mathrm{ZrO}_{2}$ system leading to higher and faster diffusion of $\mathrm{NiO}$ along with $\mathrm{Y}_{2} \mathrm{O}_{3}$ in $\mathrm{ZrO}_{2}$. The group has already prepared fully calcium stabilized zirconia by microwave processing within five minutes at $1100^{\circ} \mathrm{C}$ (Singh et al 2007). The reaction between $\mathrm{NiO}$ and $\mathrm{Y}_{2} \mathrm{O}_{3}$ by the microwave energy has not been studied in this work.

Figure 9 shows SEM of $0 \cdot 3 \mathrm{Ni}-\mathrm{YSZ} \mathrm{MW}$ (figure 9a), $0 \cdot 3 \mathrm{Ni}-\mathrm{YSZ} \mathrm{CON}$ (figure 9b), $0 \cdot 4 \mathrm{Ni}-\mathrm{YSZ} \mathrm{MW}$ (figure 9c) and $0 \cdot 4 \mathrm{Ni}-\mathrm{YSZ} \mathrm{CON}$ (figure $9 \mathrm{~d}$ ). From comparison of figures $9 \mathrm{a}$ and $\mathrm{b}$, it is observed that the grains of $\mathrm{ZrO}_{2}$ has grown uniformly in the microwave processed $0 \cdot 3 \mathrm{Ni}-\mathrm{YSZ}$ MW and the distribution of holes are uniform whereas in case of conventionally processed $0 \cdot 3 \mathrm{Ni}-\mathrm{YSZ} \mathrm{CON}$, the formation of segregated holes due to inhomogeneous distribution of $\mathrm{NiO}$ is observed. Similarly, the SEM of $0.4 \mathrm{Ni}-$ YSZ MW (figure 9c) shows more uniform grain growth as compared to the sample, $0 \cdot 4 \mathrm{Ni}-\mathrm{YSZ} \mathrm{CON}$ (figure 9d). Uniform distribution of $\mathrm{Ni}$ in YSZ matrix is one of the important factors which improves the property of Ni-YSZ cermet in terms of conductivity and reduces thermal mismatch with YSZ. The Ni distribution is more uniform in $0.30 \mathrm{Ni}-\mathrm{YSZ} \mathrm{MW}$ and $0.4 \mathrm{Ni}-\mathrm{YSZ} \mathrm{MW}$ as compared to the corresponding cermets derived from their composites obtained by conventional processing. This suggests that the microwave processing may be used to fabricate composite, $\mathrm{NiO}-\mathrm{YSZ}$, even from mixtures of $\mathrm{NiO}, \mathrm{Y}_{2} \mathrm{O}_{3}$ and $\mathrm{ZrO}_{2}$. The electrical properties of composites and cermets prepared are yet to be investigated.

\section{Conclusions}

(I) Microwave processing leads to the formation of $m \mathrm{NiO}$ $(1-m) \mathrm{YSZ}$ composite of compositions $(m=0 \cdot 2,0 \cdot 3,0.4$, 0.5 and 0.6 ) having single cubic phase YSZ. Solid solu- tion of YSZ does not form during the conventional processing of $m \mathrm{NiO}-(1-m) \mathrm{Zr}_{0.9} \mathrm{Y}_{0.1} \mathrm{O}_{1.95}$ for $m=0.2$ and 0.3 . It suggests that during microwave processing an additional driving force works which leads to the faster diffusion of ions resulting in the formation of solid solution.

(II) The cermets obtained from reduction of microwave processed composites have more uniform grain growth as compared to that obtained from conventionally processed composites.

\section{Acknowledgements}

We wish to acknowledge the financial support provided by AICTE, New Delhi, to carry out this research work and the Institute Instrumentation Centre, Indian Institute of Technology, Roorkee, for characterization of material by XRD and SEM.

\section{References}

Agrawal D K 1998 Curr. Opin. Solid St. Mater. Sci. 3480

Aruna S T, Muthuraman M and Patil K C 1998 Solid State Ionics 11145

Chen S and Shen P 1989 Mater. Sci. Eng. A114 159

Chen S, Shen P and Gen D 1992 Mater. Sci. Eng. A158 251

Chen S, Deng W and Shen P 1994 Mater. Sci. Eng. B22 247

Cheng J P, Agrawal D K, Komarneni S, Mathis M D and Roy R 1997 Mater. Res. Innovat. 144

Clark D E, Sutton W H and Lewis D A (eds) 1997 Microwaves: Theory and application in materials processing IV, Ceram. Trans. 80 (Ohio: The American Ceramic Society) pp 61

Duran P, Tartaj J, Capel F and Moure C 2003 J. Eur. Ceram. Soc. 232125

Esposito V, Ottavi C D, Ferrari S, Licoccia S and Traversa E 2003 Proceedings - Electrochemical Society VII (eds) S C Singhal and M Dokiyaln (New York: The Electrochemical Society Inc.) pp 643-652

Fukui T, Ohara S and Mukai K 1998 Electrochem. Solid-State Lett. 1120

Ingel R P and Lewis III D 1986 J. Am. Ceram. Soc. 69325

Jiang S P and Chan S H 2004 J. Mater. Sci. 394405

Khor K A and Guy Y W 2000 Thin Solid Films 372104

Knauth P and Tuller H L 2002 J. Am. Ceram. Soc. 851654

Kondo H, Sekino T, Kusunose T, Nakayama T, Yamamoto Y and Niihara K 2003 Mater. Lett. 571624

Kuzjukevics A and Linderoth S 1997 Solid State Ionics 93255

Kuzjukevics A, Linderoth S and Grabis J 1996 Solid State Ionics 92253

Lee J -H, Heo J -W, Lee D -S, Kim J, Kim G -H, Lee H W, Song H S and Moon J -H 2003 Solid State Ionics 158225

Li Y, Xie Y, Gong J, Chen Y and Zhang Z 2001 Mater. Sci. Eng. B86 119

Marinsek M, Zupan K and Macek J 2000 J. Power Sources 86 383

Marinsek K, Zupan J and Maeek J 2002 J. Power Sources 106 178

Mathis M D, Agrawal D K, Roy R, Plovnick R H and Hutcheon R 1995 Ceram. Trans. 59533 
Meek T T, Holcombe C E and Dykes N 1987 J. Mater. Sci. Letts 61060

Minh N Q 1993 J. Am. Ceram. Soc. 76563

Newnham R E 1986 Chemtech 12732

Park Y M and Choi G M 1999 Solid State Ionics 120265

Peelamedu R, Agrawal D and Roy R 2003 Mater. Sci. Eng. B98 269

Qin C -D and Derby B 1992 J. Mater. Res. 71480

Ringuede A, Bronine J A and Frade J R 2002 Solid State Ionics 146219

Roy R, Agrawal D K, Cheng J P and Mathis M D 1997 Microwaves theory and application in materials processing $I V$, Ceram. Trans. 80 (eds) D E Clark et al (Ohio: The American Ceramic Society), pp 3

Shao G -Q, Cai H, Xie J -R, Duan X -L, Wu B -L, Yuan R -Z and Guo J -K 2003 Mater. Lett. 573287
Simwonis D, Thulen H and Dias F J 1999 J. Mater. Process. Technol. 92107

Singh A P, Kaur N, Kumar A and Singh K L 2007 J. Am. Ceram. Soc. 90789

Singh K L, Kumar A, Singh A P and Sekhon S S 2008 32nd International conference and exposition on advanced ceramics and composites proceedings (Florida: Am. Ceram. Soc.) (accepted)

Sutton W H 1989 J. Am. Ceram. Soc. Bull. 68376

Thakur O P, Prakash C and Agrawal D K 2002 J. Mater. Sci. Eng. 96221

Vaidhyanathan B, Singh A P, Agrawal D K, Shrout T R and Roy R 2001 J. Am. Ceram. Soc. 841197

Wu Z and Liu M 1997 Solid State Ionics 9365

Yadoji P, Peelamedu R, Agrawal D and Roy R 2003 Mater. Sci. Eng. B98 269 